\title{
Anal Shift: Preliminary Results
}

\author{
By Ashok J. Shah, N. Bhattacharjee, D.N. Patel, and J.R. Ganatra \\ Ahmedabad, India
}

\begin{abstract}
Background/Purpose: Perineal ectopic anus in female infants is not a very uncommon congenital anomaly. The close proximity of the ectopic anus with the vulva and the stenosed opening seen in large majority of cases necessitate some form of surgical correction. A variety of surgical procedures like cutback, posterior anal transposition, PSARP, or ASAPR, with or without diverting colostomy have been described in the literature. However, in dealing with a case of ectopic anus, the authors thought a much simpler surgical correction would suffice giving an aesthetically and functionally acceptable perineum. This new and simple surgical procedure developed by Ashok Shah, Anal Shift is described in this report.
\end{abstract}

Methods: Twelve female infants with anterior ectopic anus, between 3 and 18 months of age who had undergone surgical correction by this new method (Anal Shift) is reported. Five of these children had severe and 2 had mild anal stenosis. The new technique described in detail includes shifting and creation of a new anus in the anatomically normal site and construction of the perineal body. Colostomy was not done in any of them.
Results: The cases had been followed up for 12 to 24 months. Anal function was normal with satisfactory vulvo-anal distance without any stenosis. One patient had superficial anterior wound dehiscence; she underwent reoperation with good results.

Conclusions: Anal Shift is a simple surgical procedure. It does not necessitate lateral dissection, therefore, the rectal support and the neurovascular supply to the rectum remains undisturbed, eliminating any chance of retraction. The anterior half of the neoanus does not have a suture line, thereby minimizing the chances of stricture formation. Anal Shift appears to be a safe, simple and satisfactory surgical procedure to correct anterior ectopic anus in girls without a colostomy.

J Pediatr Surg 38:196-198. Copyright 2003, Elsevier Science (USA). All rights reserved.

INDEX WORDS: Anorectal malformations, anterior ectopic anus, anal shift.
$\mathbf{A}^{\prime}$ NORECTAL MALFORMATION (ARM) occurs in approximately 1 in 5,000 live births. High anomalies are more common in boys, whereas among low anomalies, two thirds occur in girls. ${ }^{1}$

Anterior ectopic anus is not a very uncommon variety of low ARM in girls. Children with very anteriorly placed anus with or without stenosis require treatment. Those without stenosis also do seek medical help for aesthetic reasons and constipation. ${ }^{2}$

\section{MATERIALS AND METHODS}

This is a preliminary report of 12 girls aged between 3 and 18 months. They all had anteriorly placed anus. Five infants presented with severe anal stenosis, 2 had mild, and the remaining 5 had no stenosis.

From the Department of Pediatric Surgery, Sheth K.M. School of P.G. Medicine \& Research and V.S. General Hospital, Ahmedabad, India.

Presented at Congress of Asian Association of Pediatric Surgeons held at Fukuoka, Japan, November 2000.

Address reprint request to Dr Ashok J. Shah MS, FRCS, FACS, Naranpura Nursing Home, Sanghvi High School Char Rasta, Ahmedabad-380013, India.

Copyright 2003, Elsevier Science (USA). All rights reserved. 0022-3468/03/3802-0010\$35.00/0

doi:10.1053/jpsu.2003.50042

\section{Preoperative Procedure}

Liquid diet was given for 3 days. Chemoprophylaxis and bowel preparation was done in all patients. Colostomy was not done in any of them.

\section{Operative Procedure}

In lithotomy position, parts are painted and draped. Two lateral plicating sutures C-C (Fig 1) are placed, which stretch and elevate the skin bridge between anus and vagina.

Point $\mathrm{B}$ is marked at 6 o'clock position on the skin, just behind the ectopic anus, whereas point $\mathrm{B}^{1}$ is marked at $6 \mathrm{o}^{\prime}$ clock position at the proposed site (determined by skin pigmentation and muscle stimulation) of neoanus. Line joining $\mathrm{B}^{-\mathrm{B}^{1}}$ becomes midline incision.

Incision $\mathrm{A}-\mathrm{A}^{1}$ is a transverse incision between vagina and ectopic anus. The center of line $\mathrm{A}-\mathrm{A}^{1}$ is in midline. Incision $\mathrm{A}-\mathrm{A}^{1}$ should be as long as B-B. ${ }^{1}$

First, incision $\mathrm{B}^{-} \mathrm{B}^{1}$ is made (Fig 2). If necessary, the incision can be split slightly at point $\mathrm{B}$ on the posterior margin of the ectopic opening. The posterior wall of the neoanus is freed to sufficient depth. The anterior margin of muscle complex is identified. If stenosis is present, a longitudinal cut at 6 o'clock is placed on anorectum so that sufficient size of anus can be created. The incision $\mathrm{B}^{-\mathrm{B}^{1}}$ is made first so that sufficient space created posteriorly in the perineum makes anterior dissection easy.

Incision $\mathrm{A}-\mathrm{A}^{1}$ now is made and deepened until the fibromuscular mass is divided (Fig 3). Now the dissection between rectum and vagina is carried out mainly by blunt dissection. The depth of incision $\mathrm{A}-\mathrm{A}^{1}$ should be at least half the length of $\mathrm{A}-\mathrm{A}^{1}$ to give good anovulvar distance. Care is to be taken to safeguard the rectum. 


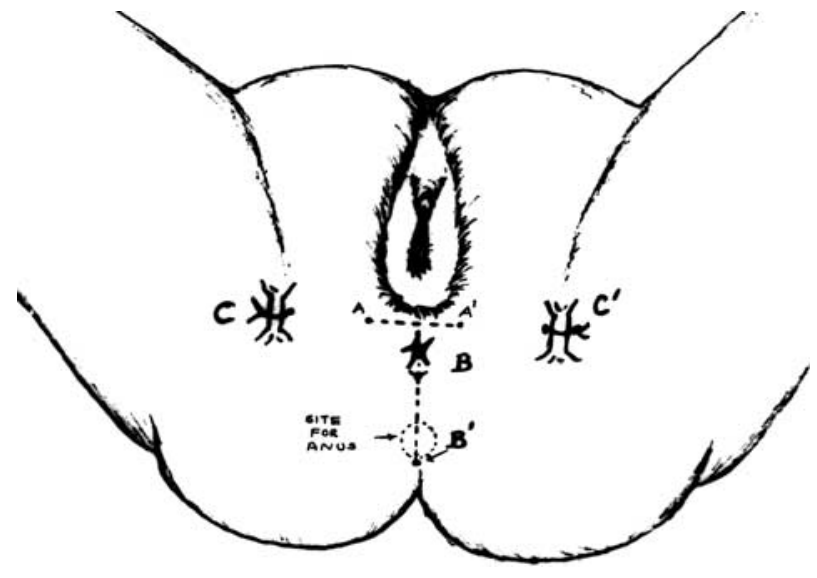

Fig 1. Female perineum with ectopic Anus. C-C1 are the 2 lateral plicating sutures, $A-A^{1}$ is the anterior transverse, and $B^{B}-B^{1}$ the posterior vertical incision, which is split marginally at point $B$. Point $B^{1}$ represents the proposed anus.

\section{Closure}

First, incision $\mathrm{B}-\mathrm{B}^{1}$ is closed. Suture is taken from point $\mathrm{B}^{1}$ to $\mathrm{B}$ or the apex of the cut end of the rectum. One or 2 lateral sutures are taken as required (Fig 4). This closure pulls the anus backwards.

Incision $\mathrm{A}-\mathrm{A}^{1}$ is closed vertically in midline, which pushes anus posteriorly. First, lateral fibromuscular mass is closed in the midline by 3-0 or 4-0 polyglycolic sutures (Vicryl). Normally, three sutures are required to gain a sufficiently sized perineal body.

A second layer of sutures is used if required. The skin also is closed vertically. Sufficient anovulvar distance is created. Anal Shift is now completed.

We recommend completing the dissection of both anterior and posterior incisions before closure. Which wound (incision) to close first, either $\mathrm{B}-\mathrm{B}^{1}$ or $\mathrm{A}-\mathrm{A},{ }^{1}$ remains a personal choice.

\section{RESULTS}

With our limited experience, the results of Anal Shift are quite promising, and none of the 12 patients had stenosis or retraction in the follow-up, which was 12 to 24 months. Good vulvoanal distance was achieved in all

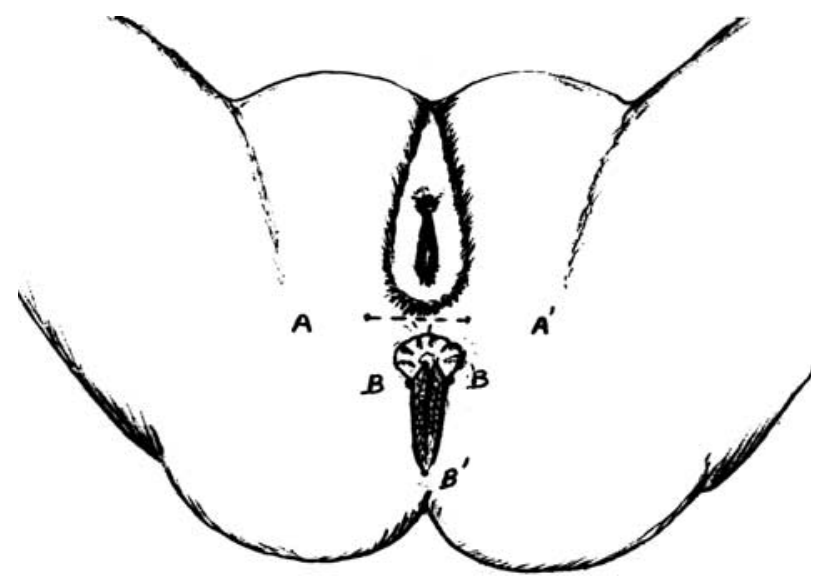

Fig 2. Dissection of incision B-B. ${ }^{1} \mathrm{~A}$ cut is made at 6 o'clock position on the anorectum to create adequate size of anal opening.

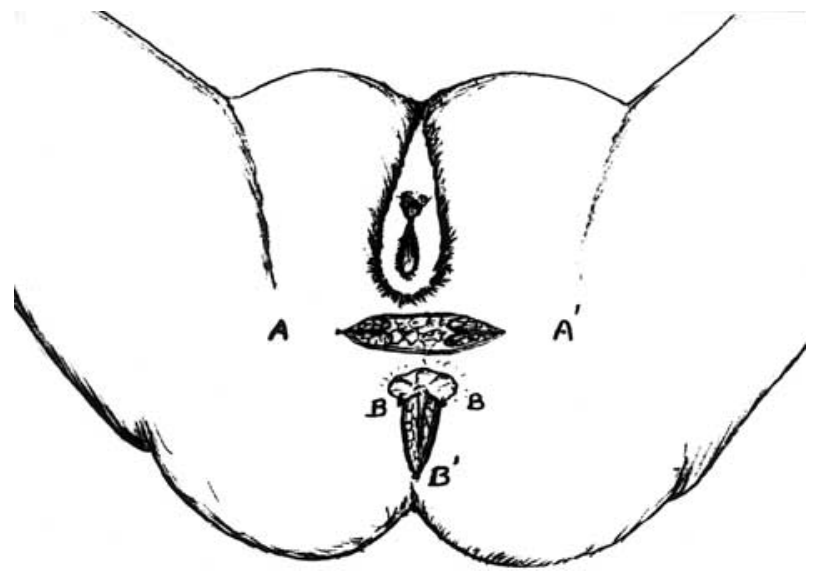

Fig 3. Anterior transverse incision $\left(A-A^{1}\right)$ is deepened to divide fibromuscular mass (between vagina and anorectum).

patients except in the first in whom it appeared that satisfactory anterior dissection was not done initially. The baby had superficial anterior wound dehiscence, which was sutured with satisfactory results.

Regular anal dilatation was not required. Calibration was done after 2 weeks, one month and 2 months after surgery. Laxatives were given in the first 5 to 7 days after surgery and then withdrawn. None of the patients required laxatives later on; however, dietary advice and toilet training was absolutely necessary. Constipation has not been a troublesome problem in our follow-up, the longest being 2 years.

\section{DISCUSSION}

The management of low ARM in female infants has been the topic of controversy since 1826 when Dieffenbach proposed the perineal-anal transplant operation. ${ }^{3}$ Potts et $\mathrm{al}^{4}$ described the technique in 1954 , which has

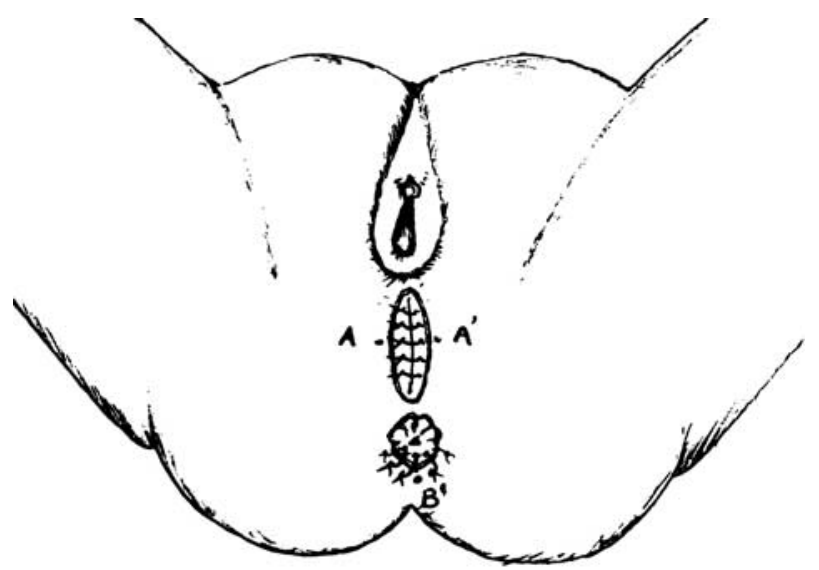

Fig 4. Closure of posterior incision followed by anterior incision. Anus shifted posteriorly with adequate distance between vagina and rectum. Note the preservation of anterior half of mucocutaneous junction. 
been used extensively for the treatment of anterior ectopic anus in girls. Undoubtedly, it is a standard operation; however, the results of this operation in others had not been uniformly satisfactory. Moderate to severe complications like anastomotic dehiscence, retraction, recurrent fistula, stenosis, and continence problems were reported in about $20 \%$ of patients. ${ }^{4-7}$

The "cut back" operation with dilatation will widen the anus; however, this procedure does not place the anus in a normal position As a result, acceptable vulvoanal distance is not achieved, and soiling of vulva might continue to occur with its associated risks, and the child is likely to have constipation off and on. Thus, this procedure does not satisfy the functional, aesthetic, and cosmetic requirements in our patients. ${ }^{8-10}$

Abeyaratne described the "Z-technique" for gaining the distance between vagina and anus. The procedure takes the anus down with its original anocutaneous margin. However, it requires considerable dissection with $20 \%$ wound infection rate and significant incidence of breakdown. ${ }^{11}$

Anterior midline approach or anterior sagittal anorectoplasty (ASARP) is being used increasingly these days for low ARM in girls with gratifying results. However, in a series of 416 patients with ASARP complications like recurrence of fistula, retraction of rectum, development of acquired perineal canal, anal stenosis, and posterior ledge occurred in 48 patients. Posterior ledge leads to intractable constipation, which requires reoperation (division of ledge and mucocutaneous apposition). ${ }^{12}$

Limited PSARP, if associated with lot of perirectal dissection, is likely to cause the most severe changes in the external appearance of the anus, bowel control, and manometric parameters. ${ }^{13-16}$ To conclude, we feel that the Anal Shift is a much simpler surgical procedure without too much perineal dissection and it gives the following benefits: (1) It preserves at least the anterior half of mucocutaneous junction of the original anus, thus, there are fewer chances of stenosis. (2) Dissection is not done laterally; therefore, neurovascular supply and lateral supports are practically not disturbed. (3) Perineal body is formed under vision. (4) Good vulvoanal distance is achieved giving aesthetically and functionally acceptable perineum. Thus, Anal Shift could be an alternative operation to all other accepted procedures in the management of anterior ectopic anus in girls. It appears to be a simple and satisfactory procedure; however, long-term experience is necessary before calling it ideal.

\section{REFERENCES}

1. Peña A, Keily EM: Anorectal malformation in O’Neill JA et al: Pediatric Surgery, vol 2 (ed 5). St Louis, MO, Mosby Publication, 1998, pp 1425-1449

2. Chatterjee SK: Anorectal malformation-Problems in neonate, in Gupta DK (ed): Textbook of Neonatal Surgery. New Delhi, India, Modern Publishers, 2000, pp 228-232

3. Dieffenbach JF quoted by Stephens FD, Smith ED: Anorectal malformation in children. Chicago, IL, Yearbook Medical Publishers, 1971, pp 114

4. Potts WJ, Riker WL, Deboes A: Congenital imperforate anus. Ann Surg 140:381-395, 1954

5. Nainan KM, Mitra SK, Pathak IC: Perineal anal transplant in anorectal malformation in female patients. Surgery 77:697-702, 1975

6. Saxena N, Bhattacharya NC, Katariya S, et al: Perineal anal transplant in low anorectal anomalies. Surgery 90:464-467, 1981

7. Swenson O, Donnellan WL: Preservation of puborectalis sling in imperforate anus repair. Surg Clinic North Am 47:173, 1967

8. Burlington JD: Rectovaginal separation: Operation after a cutback procedure for anorectal anomalies. Arch Surg 110:47-50, 1975
9. Hendren WH: Constipation caused by anterior location of the anus and its surgical correction. J Pediatr Surg 13:505-512, 1978

10. Leap LL, Ramenofsky M: Anterior anus, A common cause of constipation in children. J Pediatr Surg 13:627-630, 1978

11. Abeyaratne M: Posterior transposition of anterior ectopic anus. J Pediatr Surg 26:725-728, 1991

12. Wakhlu A, Pandey A, Prasad A, et al: Anterior sagittal anorectoplasty for anorectal malformations and perineal trauma in the female child. J Pediatr Surg 31:1236-1240, 1996

13. Brain AJL, Kiely EM: Posterior sagittal anorectoplasty for reoperation in children with anorectal malformation. Br J Surg 76:5759, 1989

14. Peña A: Imperforate anus and cloacal malformations, in Ashcraft KW: Pediatric Surgery (ed 3). Philadelphia, PA, Saunders, 2000, pp 473-492

15. Peña A: Anorectal anomalies, in Prem Puri: Newborn Surgery (ed 1). Butterworth-Heinemann Publications, 1996, pp 379-394

16. Peña A, Amroch Dan, Baeza Carlos, et al: The effects of posterior sagittal approach on rectal function (experimental study). J Pediatr Surg 28:773-778, 1993 